\title{
Hunterian Museum bicentenary: 1813-2013
}

\author{
E. Williams ${ }^{1}$
}

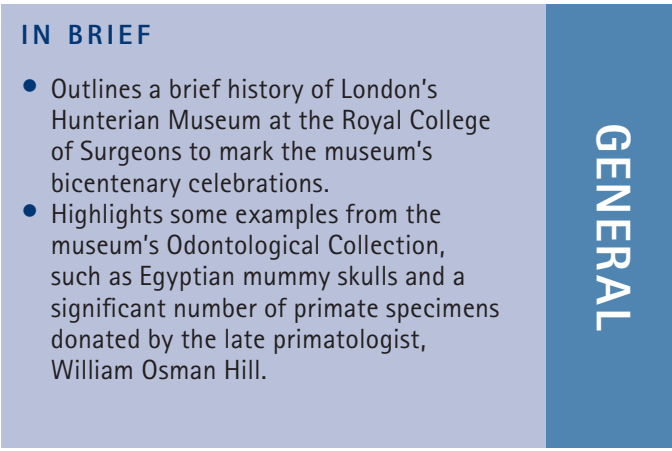

The Hunterian Museum is celebrating its bicentenary in 2013, an ideal time for reflection of its notable origins and the his-
tory behind its fascinating collection of human and animal anatomy that tells the story of surgeons and surgery over the
last two centuries. The Odontological Collection is an unparalleled source of dental information, with a vast assortment of
teeth and cranial bones, which should not be missed.

\section{INTRODUCTION}

The Hunterian Museum, at the Royal College of Surgeons, houses a fascinating collection of human and animal anatomy that tells the story of surgeons and surgery over the last two centuries. The museum, which celebrates its bicentenary in 2013, also boasts a vast odontological collection consisting of a wide range of cranial and dental material, including Winston Churchill's partial upper denture and three Egyptian mummy skulls. This article aims to highlight the rich history of the museum and places particular focus on the odontological collection of teeth and cranial bones.

\section{ORIGINS}

On the 18 May 1813 the Royal College of Surgeons opened a museum based on surgeon-anatomist John Hunter's collection. One of the founders of scientific surgery, Hunter amassed the most comprehensive collection of human and animal anatomy specimens in eighteenth century Europe. He used them as an essential part of medical education to teach pupils the complex structures of the human body.

'Royal College of Surgeons, 35-43 Lincoln's Inn Fields, London, WC2A 3PE

Correspondence to: Esther Williams

Email: ewilliams@rcseng.ac.uk

Accepted 29 April 2013

DOI: $10.1038 /$ sj.bdj.2013.631

${ }^{\bullet}$ British Dental Journal 2013; 215: 41-43
It was during Hunter's time serving as a military surgeon that he began to collect material for his anatomical collection. His combined experience of dissecting specimens and wartime surgery ignited an interest in the functions of the body that would continue throughout his life. Early on in his career he set up as a dental surgeon, even though dentists were then regarded with suspicion by many surgeons. His knowledge of anatomy played a huge part in the development of dentistry. While at his brother's anatomy school Hunter examined countless bones, teeth and jaws. His work with the dentist James Spence gave him a deep understanding of tooth decay, disease and dental pain. In Hunter's book, The natural history of the human teeth $(1771)^{1}$ he introduced the terms bicuspids, cuspids, incisors and molars. In his follow up, A practical treatise on the disease of the teeth (1778), ${ }^{2}$ he detailed dental and oral pathology and described his work on the transplantation of teeth. Preparations he made for this work are on display in the museum.

The origins of the Odontological Collection date back to the 1850 s, when the creation of a museum was proposed in the Annual General Meeting of the Odontological Society of Great Britain. The society members at this meeting included eminent surgeons such as Sir Edwin Saunders (1814-1901; the former dental surgeon to Queen Victoria) and Sir John Tomes (1815-1895). They all backed

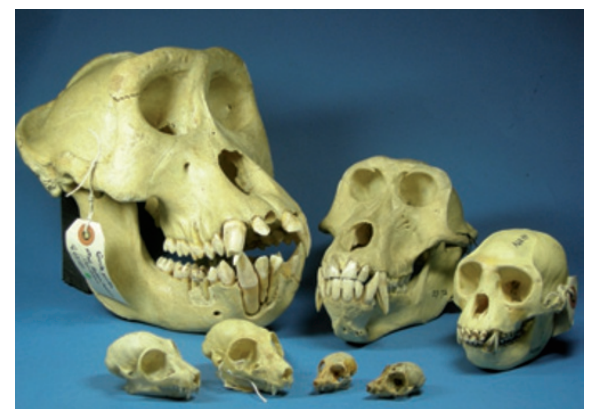

Fig. 1 A selection of primate skulls from the Odontological Collection

the proposal and their strong reputations were central to the agreement to establish an odontological museum, which developed into an unparalleled resource centre for dental anatomy and pathology. Tomes, Saunders and their fellow members of the Odontological Society were instrumental in the creation of the Licentiate in Dental Surgery of the Royal College of Surgeons of England. In 2010 a temporary exhibition commemorating the life and work of Sir John Tomes was installed in the Hunterian Museum. The Odontological Collection specimens formed the basis of this display.

In the early 1900s the Odontological Society was incorporated into the newlyformed Royal Society of Medicine. The relocation of the society resulted in the temporary loan of the museum's collection to the Royal College of Surgeons. In 1943 this transfer was declared permanent as a goodwill gesture towards reconstitution of the museum, which was damaged by bombing in 1941. The odontological material was initially placed on public 
display in the college's Hunterian Museum. Following a major refurbishment of the museum, completed in 2005, some of the Odontological Collection (Fig. 1) has now been integrated into the museum displays, while the bulk resides in store as a research collection.

\section{HUNTERIAN MUSEUM THROUGH THE YEARS}

Over the last 200 years specimens from a variety of sources have been collated; the majority having been donated by renowned surgeons, dentists, anthropologists and zoologists. Over 10,000 human and animal specimens are contained in the collection. One example that will form part of a special bicentenary exhibition will be the skull of a wild boar, whose anterior mandible has been affected by actinomycosis, a bacterial infection (Fig. 2).

Some specimens are of particular historical interest, such as the short twine necklace of 38 human teeth brought back from the Congo River by the explorer Henry Morton Stanley, or the selection of teeth retrieved from soldiers who died during the battle of Waterloo in 1815. Donations to the collection have lessened over the past century, largely due to the sheer volume and diversity of the material currently held. The most recent contribution was Sir Winston Churchill's partial upper denture, which was designed for him by his dentist Wilfred Fish (1894-1974) and donated to the collection in 2000 (Fig. 3).

The human material is a crucial resource for the study of dental development, as all ages are represented, both in skeletal form and in casts or models. These include over 200 sets of perinatal dentitions that were collected during the 1950s.

Examples include specimens that illustrate abnormalities in dental placement, from simple transpositions to eruption through the zygomatics or even into the nasal fossa. All varieties of non-metric traits have been noted in the extensive array of individual mounted teeth showing the gradations of such anomalies. Sets of molars have therefore been mounted to display the varying degrees of supernumerary cusps, such as parastyles and cusps of Carabelli. Similarly, traits such as microdontia, anodontia and the presence of supernumerary teeth can be seen in prepared sections of mandible and maxilla.
This includes remains from seven Romano-British sites, the large majority of which have complete dental arcades and generally show little displacement or disease. In addition to this, over 100 cranial specimens have been donated from two medieval burial sites in central London. Both of these populations show a range of non-metric traits and pathologies, including microdontia, supernumerary teeth and diseases that generally correlate with poor oral hygiene. Finally, there is a broad geographic range of archaeological sites represented in the collection, including three Egyptian mummy skulls and four Guanche mandibles (the indigenous inhabitants of the Canary Islands).

There are a few human specimens housed within the collection that do not relate specifically to the categories of development or pathology, but are potentially of a wider anthropological value. Such examples include the several skulls displaying variations in intentional modification of the dentition through dental filing, chipping, staining or ablation. Casts have been included alongside this sample to show variations in modification between cultural groups. A large proportion of these crania are Javanese in origin, having been donated by the anthropologist Joseph Barnard Davis in the late nineteenth century. The effect of occupational or habitual activities on the dentition is a related theme. Such use of the teeth as a tool is noticeable in the casts of Inuit people's teeth depicting the practice of leather softening through mastication and the various sections of jaws showing pipe facets.

Over the past three years human material has formed the crux of several studies in a variety of disciplines. The themes researched from the human collection have included dental wear and its use in age estimation, investigations into ancient trepanning, the implementation of craniometry in elucidating provenance and the assessment of links between cribra orbitalia and porotic hyperostosis.

While approximately one third of the collection is composed of human material, the remaining two thirds consist of crania from a range of faunal taxa. of the 7,000 plus animal cranial specimens, some 2,000 are primates, including a

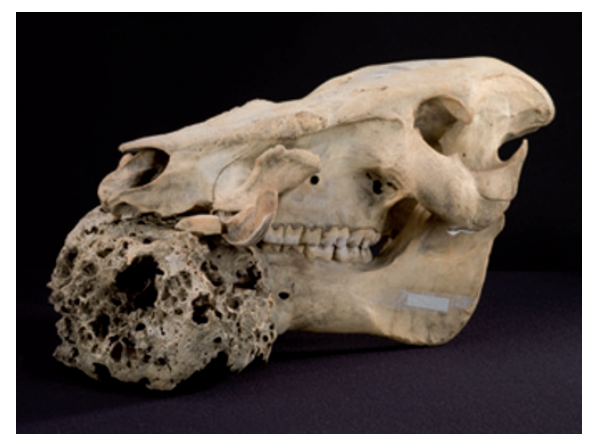

Fig. 2 Skull of a wild boar, whose anterior mandible has been affected by actinomycosis

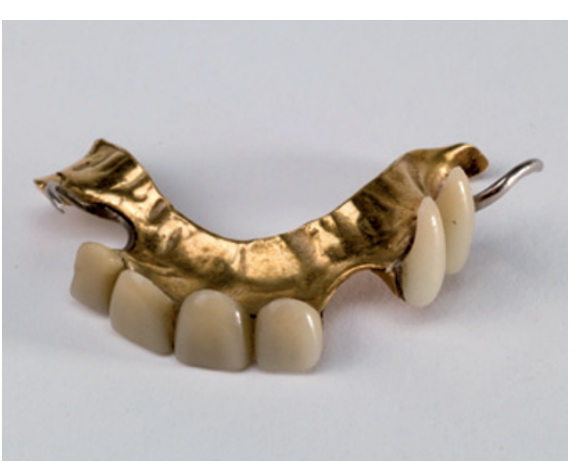

Fig. 3 Winston Churchill's partial upper denture

significant number of specimens donated by the late primatologist, William Osman Hill (1901-1975). A wide variety of primates are represented in the collection, from the largest in the world, the gorilla, to one of the smallest, the dwarf lemur. This diversity in both animal subspecies and geographic habitat holds the potential for extensive comparative anatomy studies.

The pathological human collection has been assembled over the years to present an array of diseases from dental caries to phossy jaw. All of the common dental pathologies, such as dental calculus, periodontitis and various forms of abscesses, are represented in the collection alongside those which could be considered exceptional examples of pathology, such as hypoplasia of the mandibular ramus and dentitions displaying congenital syphilis. In addition to the skeletal and dental specimens, the large collection of dental casts illustrates a range of diseases, injuries and abnormalities: from congenital abnormalities such as cleft palates, to maxillofacial gun-shot injuries of soldiers from the First and Second World wars.

\section{CONCLUSION}

The Odontological Collection is an 
unparalleled source of dental information. It is hoped that in this bicentenary year this overview will prompt all those in the dental profession to refer to the collection in future studies and research.

1. Hunter J. The natural history of the human teeth London: J Johnson, 1771.

2. Hunter J. A practical treatise on the disease of the teeth. London: J Johnson, 778.
The Hunterian Museum bicentenary exhibition opened on 14 May 2013 and runs until 9 November 2013. Key exhibits at the special exhibition include: the skull of a wild boar that shows the anterior of the mandible affected by actinomycosis, corrosion casts of the human heart and lung, and next generation surgical training models. Exhibition entry is free of charge and the museum is open from Tuesday-Saturday, $10 \mathrm{am}-5 \mathrm{pm}$. All museum specimens are listed on the online catalogue 'surgicat' and can be searched by anyone who has access to the internet at http://surgicat.rcseng.ac.uk.

For further information on the museum collections please contact the museum's department (museums@rcseng.ac.uk) or visit www.rcseng.ac.uk/museums/hunterian. 